\title{
Rising above a cause-and-effect stance in mathematics education research
}

\author{
John Mason ${ }^{1}$
}

Published online: 17 June 2016

(C) Springer Science+Business Media Dordrecht 2016

René Descartes was strongly influenced by the cuckoo clock: the idea of a mechanism with logical and necessary consequences as a metaphor for human experience. Pierre-Simon Laplace applied this mathematically by claiming that if he had all the initial conditions at some point in time, then he could predict everything subsequently. The cuckoo clock mechanism metaphor, complete cause-and-effect, underpinned the enlightenment and the industrial revolution, because mechanisms can be engineered to be independent of time, place, situation and conditions.

So why is this aspect of Descartes and Laplace still influential in mathematics education? Why does so much research in mathematics education keep chasing a will o' the wisp, pursuing a magic ring whose presence would provide a primary explanation and predictor of effective teaching and proficient learning? This continues even though it is commonly acknowledged that learning is highly contingent, and that mathematics learning is especially so. It is influenced by time, place, situation, conditions, dispositions, recent and long-term past experience, and colleagues, the topic, pedagogical actions, .... The list continues.

Nevertheless, people continue to ask questions such as "what does effective teaching of mathematics look like?" and "What must teachers know in order to teach effectively?". This despite rich experience that what 'knowledge' teachers have displayed in the past, what actions they have written essays about or even enacted in the past, does not enable prediction of what actions will be enacted in the future. Even shared development of a lesson does not lead to the same lesson being enacted, because the people and the situation are subtly different (Kuhlberg 2007).

It is strange that in a world in which attempts to construct walking robots by controlling all their components failed, whereas allowing feedback loops to operate enables the mechanism as a whole to walk reasonably naturally, we persist in trying to control things

John Mason

John.mason@open.ac.uk

1 University of Oxford and the Open University, 27 Elms Rd, Oxford OX2 9JZ, UK 
from the centre. Industry, and certainly education, retains the pyramid structure of power and control. The 1980's slogan of accountability, which now so clogs our institutions with form-filling and back-watching has been activated through central control: each person in the chain of command feels the need to be assured that those carrying out policy for them are behaving appropriately. Organic growth and transformation are stymied. The result is stagnation and fear of innovation. Yet at the same time people cry out for innovative practices in education, problem-solving, creativity and the like, as if somehow an innovative practice injected into a moribund system is likely to enliven it.

We desperately need research which sees and conceives of the classroom as an organic whole, in which both individuals and the collective display qualities of complexity (life). This will necessarily include seeing and conceiving of the educational institution as itself an organism, within an educational nexus within a state-guided system. Such a stance could not only bring freshness to how we see education, but could release much desired creativity and liveliness. This is the stance of complexity theorists (Davis et al. 2006).

As a domain of study, mathematics education has become proud of its multi-disciplinary approach, drawing on (the foci of, the fads of) other disciplines. These sweep over one another like waves on a beach. Constructivisms (of various sorts), constructionism, and theories with adjectives such as socio-cultural, socio-historical, political, critical, identity, positioning, attribution, situated cognition and variation have all taken the limelight for a period of time, then proved inadequate and so abandoned. The waves keep breaking on the beach, attracting attention, then being overlaid, partly because they fail as universal panacea, and partly because it is easier to ride a fresh wave than to probe deeply into the consequences of an earlier wave.

Learning and teaching are fundamentally relational. My relation with my students and my relation with mathematics interweave to influence how I am with students and colleagues and so afford what is possible (Mason 2008, 2014). These relationships co-evolve, because responsiveness to student concerns and states influences what can be said and done, and what is said and done reciprocally influences the state of individuals and the state of the class as a whole. They are not only complex, but full of complexity, in the full sense of the term: multiple factors and components in a complex web of inter-relatedness. They involve development, co-emergence and variety.

Every teacher act, every student reaction, re-feeling, response, every shift of attention is part of the transformation of the situation which involves teacher, student and mathematics within the milieu of classroom, institution and education system. What looks like the same pedagogical act enacted by a teacher in two different situations can lead to widely varying attributes of the system in both the short and the long term. This is characteristic of complexity. Terms used to capture that complexity (Davis et al. 2006) include fractal, recursive and self-organising or auto-poetic (Maturana and Varela 1972, 1988).

Taking a systemic stance retains the complexity rather than trying to reduce phenomena to simple components whose qualities when analysed independently may or may not be present in the full system. Instead of seeking illusive stable or robust outcomes from micromanaging a few components, a systemic approach recognises that it may or may not be possible to identify 'strange attractors' which are redolent of certain types of complex situations.

For example, documenting the deficiencies of novice teachers and students simply contributes to the general malaise of teaching and learning mathematics as inadequate and ineffective. Tracking changes in learner proficiency over time, or teacher use of pedagogic actions over time underpins a linear trail of development rather than elaborating the complexity of change and development, of what is possible in-the-moment or on-the-fly. 
Even the terms growth and development carry with them the frozen metaphor of "progress as a staircase' rather than contributing to a metaphor of 'emergence of complexity', of 'folding back' (Pirie and Kieren 1989, 1994) so that

We shall not cease from exploration

And the end of all our exploring

Will be to arrive where we started

And know the place for the first time. (Eliot: Little Gidding).

One of the contributions of the Discipline of Noticing (Mason 2002) is that it circumvents a cause-and-effect stance. It offers practical techniques for noticing opportunities in-themoment to act freshly rather than habitually. It is not about accumulating a collection, or worse, a sequence of pedagogical acts which are claimed to have specific effects. Rather it is a systematic method of enriching the affordances and the repertoire of available actions so that in-the-moment choices are available. It is about recognising and seizing opportunities to act freshly, rather than being condemned to act mechanically out of habit. It is not about finding the 'best action' to initiate when students act, emote, or respond in a particular way, but about enabling a choice to be made, a momentary taste of freedom of action, consonant with the teacher's apprehension of the situation in all its complexity. The more narrow and tunnel-visioned the awareness of the teacher, the fewer the actions that are available to be enacted, the simpler the situation as perceived and apprehended, and so the greater the chance that complexity is lost.

Repeatedly refining distinctions (for example as is currently happening in studies of enculturating learners into mathematical reasoning) can only be of value if it contributes to a refinement of how we sense the complex web of inter-dependencies and relationships, rather than implying that a sufficiently refined set of distinctions will somehow make it possible to engineer suitable acts of teaching whose outcome will be enhanced proficiency for learners. As Davis (Lectures 2014) points out, even the notion of 'outcome' invokes the metaphor of input-output and mechanicality.

The human psyche is made up not only of enaction, affect and cognition, but of attention, will and witness. Preparing a lesson or sequence of lessons is about bringing to mind the web of possible shifts of attention that participants might experience (not simply what is attended to, but in what ways). Teachers' choices will not cause learners to experience something, but they can enrich possibilities, the opportunities for learners. "I cannot do the learning for my students". In other words, student will is significant: taking initiative is a necessary and unavoidable part of learning. Tasks can help prepare learners to be able to hear and see what is being said and done, with and in front of them. Different students may experience different trajectories through the teacher's Web perception, but with care suitable constraints can be imposed so that attention does not simply go 'everywhere'. A successful lesson in mathematics is not one that could or does 'go anywhere', but one in which the teacher has a rich collection of resources to invoke depending on their sense of the topic and on what they are sensitised to notice happening, much of which can be anticipated.

I have long sought an alternative to cause-and-effect as a suitable mechanism for describing education. The best I have been able to find is the metaphor of 'primordial ooze', or if you prefer, a complex chemical soup. There are multiple factors (chemicals) at play, with a dynamic consisting of combining and breaking up of identifiable or discernible components. Overall there may be a dynamic equilibrium (a 'strange attractor') or there may be casual or abrupt drift of some sort. 
One weakness of the metaphor is that the notion of chemicals suggests atomic components, whereas when probed, the analogue to chemicals are flows of energy along neural networks altering the attributes of those networks, and at a larger grain-size, aspects of the human psyche being energised in broadly characteristic yet situationally specific ways. But further analysis of the human psyche reveals further complexity, in that, for example, cognition, affect and enaction are themselves complex inter-related formations (Ouspensky 1950). It is only recently that the human psyche has been acknowledged to go beyond cognition, affect and enaction to include attention, will and witness. The latter can be developed through practices such as those in the Discipline of Noticing.

I look to mathematics education to catch up with the zeitgeist of the times, to confine to the filing cabinet studies of what people can and cannot do, even when the studies are more appropriately cast as 'did and did not do'. Let us focus attention on the web of influences on specific classroom moments, being content for the moment to chart their multiplicity, and to reach out for techniques for studying complex systems. Charting the presence of feed-back loops which manifest structural-coupling (Maturana and Varela 1988) within the web could enrich teacher awareness, providing them with yet further actions to initiate in response to learners' actions. Detailed studies of components are one contribution, but cannot be effectively acted upon, cannot be effectively used to influence policy unless they are seen as part of a much greater whole.

\section{References}

Davis, B. (2014). EDUC 420 Lectures. Calgary: Werklund School of Education, University of Calgary.

Davis, B., Summara, D., \& Simmt, E. (2006). Complexity and education: inquiries into learning, teaching and research. Mahwah: Lawrence Erlbaum.

Kuhlberg, A. (2007). Can lessons be repeated? In J. H. Woo, H. C. Lew, K. S. Park, \& D. Y. Seo (Eds.), Proceedings of the 31st conference of the international group for the psychology of mathematics education (Vol. 3, pp. 121-128). Seoul: PME.

Mason, J. (2002). Researching Your own Practice: The Discipline of Noticing. London: RoutledgeFalmer.

Mason, J. (2008). Being mathematical with \& in front of learners: attention, awareness, and attitude as sources of differences between teacher educators, teachers \& learners. In T. Wood (Series Ed.) \& B. Jaworski (Vol. Ed.), International Handbook of Mathematics Teacher Education: The Mathematics Teacher Educator as a Developing Professional (Vol. 4, pp. 31-56). Rotterdam: Sense Publishers.

Mason, J. (2014). On being mathematical with and in front of learners. Calgary: Killam Scholar Lecture, Werklund School of Education, University of Calgary.

Maturana, H., \& Varela, F. (1972). Autopoesis and cognition: The realization of the living. Dordrecht: Reidel.

Maturana, H., \& Varela, F. (1988). The tree of knowledge: The biological roots of human understanding. Boston: Shambala.

Ouspensky, P. (1950). In search of the miraculous: Fragments of an unknown teaching. London: Routledge \& Kegan Paul.

Pirie, S., \& Kieren, T. (1989). A recursive theory of mathematical understanding. For the Learning of Mathematics, 9(4), 7-11.

Pirie, S., \& Kieren, T. (1994). Growth in mathematical understanding: How can we characterise it and how can we represent it? Educational Studies in Mathematics, 26(2-3), 165-190. 